\title{
Evaluating the decision on choosing fishing ground for artisanal fisheries using spatial and Fuzzy DEMATEL in small islands: Sustainability driven
}

\author{
Syahibul Kahfi Hamid ${ }^{a}$, Wellem Anselmus Teniwut ${ }^{a^{*}}$, Maimuna Renhoran ${ }^{\mathrm{b}}$ and Roberto Mario \\ Kabi Teniwut ${ }^{\mathrm{a}}$
}

${ }^{a}$ Fisheries Agribusiness Study Program, Tual State Fisheries Polytechnic, Langgur City, Southeast Maluku Regency, 97611, Indonesia ${ }^{b}$ Fishing Technology Study Program, Tual State Fisheries Polytechnic, Langgur City, Southeast Maluku Regency, 97611, Indonesia

\begin{tabular}{l}
\hline C H R O N I C L E \\
\hline Article history: \\
Received July 14, 2020 \\
Received in revised format: \\
July 25, 2020 \\
Accepted August 102020 \\
Available online \\
August 10, 2020 \\
\hline Keywords: \\
DEMATEL \\
Spatial \\
Artisanal fisheries \\
Sustainability
\end{tabular}

\begin{abstract}
A B S T R A C T
The maintenance of a sustainable mechanism to curb the rate of overfishing in similar water zones is one of the major challenges facing artisan fisheries in small island regions. Several factors instigate the decision by local fishermen to potentially choose a location to explore. Obviously, the demand to address these triggers, particularly those with negative impact tendencies, has become paramount. This study, therefore, is aimed at mapping out fishing heat spots based on arrival, background of the fishermen, and available species. Subsequently, an evaluation is conducted to ascertain the criteria influencing the decision on a specific position and also to determine the consequences of their negative impact on marine resource sustainability and coastal community welfare. For these reasons, data from fishermen, sellers and local distributors were collected by using questionnaires, and analyzed to generate useful information on related fishing ground. Furthermore, experts were involved in providing expert assessment for Fuzzy Decision Making Trial and Evaluation Laboratory (DEMATEL). The results showed significant insights and therefore offer support to help regulators preserve marine resources, especially by updating their decision making capacity for increased coastal community welfare. The direct implication of this research also serves as a basis for conducting traditional fisheries, estimated not only to meet economic impact, but also promote sustainable environment.
\end{abstract}

\section{Introduction}

The environmental and social factors, including culture and safety, are significant considerations during the decision making process in an effort to determine the possible position of fishing ground. These are not only applicable to fishermen in Kei islands, but also extend to counterparts across the world. The influences are predominantly economical, although, there is a behavioural tendency threatening sustainable biodiversity in certain marine waters, specifically among local fishermen. This is attributed to fishing activities that do not only affect the fish, but other non-targeted marine species (Hall \& Mainprize 2005). In addition, conventional small-scale fishermen are more prone to adopt outdated knowledge and practices, rather than explore opportunities in modern technology (Defeo \& Castilla, 2005; Castilla \& Defeo 2001). This situation causes low catch range in coastal regions, hence instigates urgent need to preserve marine resources in small regions, including Kei Islands, Indonesia. Controlling the behaviour of fishermen is significant in averting possible crisis related to marine resources, and associated with illegal fishing or overfishing. This also tend to result to changes in the surrounding ecosystem (Myers \& Worm, 2003; Netek et al., 2018). However, some recommended solutions include to reduce capture capacity (Barkin \& DeSombre, 2013), zone heat spots (Client et al., 2010), upgrade technology expansion, and modify fishing behaviour (Pauly et al., 2003). The fishing capture potential in Kei Islands and Maluku Province is fast becoming a major income source for fishermen. However, considering current trends and conditions related to behaviour, fleets and techniques, including illegal fishing, the tendency of marine resource development for a particular fish specie, is expected

* Corresponding author.

E-mail address: wateniwut@polikant.ac.id (W. A. Teniwut)

(C) 2020 by the authors; licensee Growing Science, Canada. doi: $10.5267 /$ j.dsl.2020.8.001 
to decline in the next 8 - 10 years (Klein et al., 2010; Teniwut, 2016). Therefore, a study is crucial in order to maintain the level of marine resource sustainability, especially fishing. Furthermore, the use of modern technology is strongly advised in view of the complex factors influencing aquatic reserves. This triggers the requirement for multidisciplinary and multimethodological approach towards tackling the specific problem (Ren et al., 2012; Kandakoglu et al;. 2009; Lee \& Wu, 2014; Adamides et al., 2009). Regulating fishing grounds poses a complicated challenge. This is due to a high level dependency on sea. Nevertheless, coastal communities generally recognize the importance in preserving marine supplies, and therefore tend to offer support towards implementation of Marine Protected Area (MPA) (Hamid et al., 2017). The selection of MPA locations is very imperative in balancing environmental sustainability, economic resilience, and coastal community welfare. In general, there is need to improve performance and technological capacity in order to compete and boost income, both for fishing and aquaculture (Teniwut, 2018). Also, selecting the best solution to solve a problem with a high impact is necessary, despite several complex factors. Therefore, one method commonly applied is MCDM. The multi criteria decision making (MCDM) approach is widely used to resolve complex objectives and constraints (Wang et al., 2009; Rezaei, 2015; Kiker et al., 2005; Govindan et al., 2015; Zopounidis \& Doumpos, 2002). A typical example is DEMATEL (Decision making trial and evaluation laboratory), and is extensively employed in identifying causal chain components of complex systems to describe critical factors influencing decision making (Gabus \& Fontela, 1972). The method is applied in various fields including problem solving as either standalone or combined with other MCDM methods, for instance, intertwined e-learning (Tzeng et al., 2007), online stores (Chiu et al., 2013), airlines (Chen, 2016), vehicle maintenance (Vujanovic et al., 2012 ), tourism (Liu et al., 2012). The precision of DEMATEL is significantly improved with a combination of fuzzy logic based on the provided recommendations to actual field conditions, such as research conducted by (Wu et al., 2007; Chang et al., 2011; Lin, 2013). In addition, the study encapsulates the application of spatial analysis to process heat map data density for fishing ground in Kei Islands. This helps to comprehensively represent the locate spots with exceeding capacity and vice versa, and also enables deeper analysis of decision making in terms of determining fishing locations. Furthermore, the paper is divided into several sections, where the first part depicts the content of the Introduction as the primary reasons and justification for the study. The second shows the methodology comprised of various stages, analytical tools applied, and data collection techniques, while the third is result, and then fourth corresponds to the discussion. Finally, the fifth is the conclusion summarizing the research purposes, including limitations and implications.

\section{Methodology}

\subsection{Study Locations}

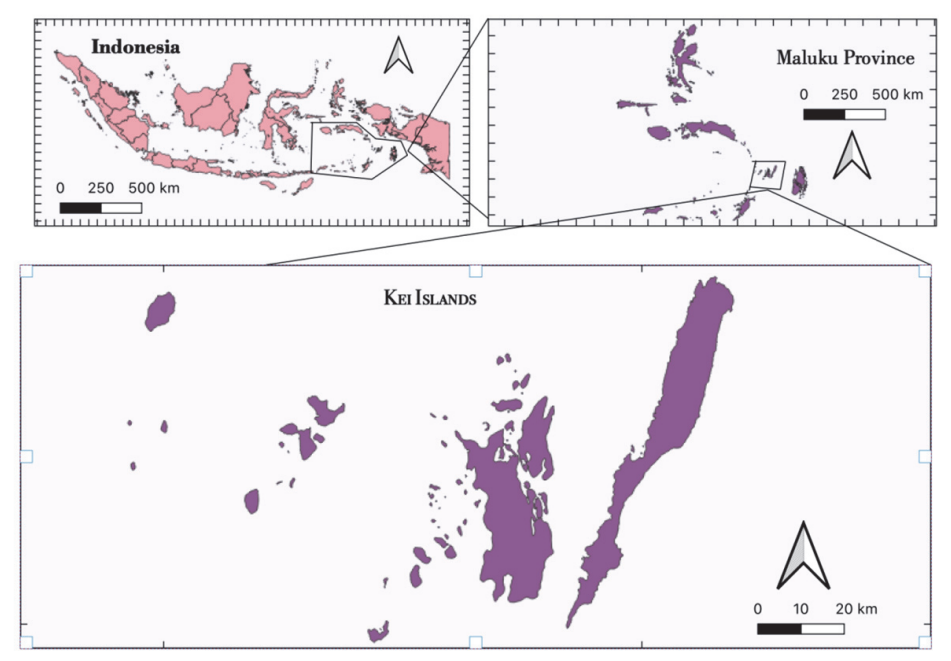

Fig. 1. Study Locations

Fig. 1 shows Kei Islands comprised of three large types, termed, Kei Besar, known as the largest island, Kei Kecil, and Dullah. Moreover, hundreds of small islands, both inhabited and abandoned, currently exist. Fisheries and agriculture are the two primary sources of coastal communities, where fisheries activities are the first and most consistent choice compared to fish farming and other related interest. The hereditary habits, economic drive, and available local markets are the primary contributing factors, irrespective of poor turnover due to lack of stable outcome, and limited managerial proficiency.

\subsection{Data Collection}

Two analytical tools were applied, including spatial analysis to represent heatmap of fishing ground locations, and DEMATEL with fuzzy logic measurements to determine the factors influencing the choice of spot. Also, two data collection methods were automatically selected, where the first indicates field survey using questionnaires and the second involves field verification on sellers, landing spots and fishing villages by collecting the fishing ground location data. These processes 
were conducted between June 2017 to June 2018 and about 3036 datasets were generated. Furthermore, for Fuzzy DEMATEL, the fishermen were requested to confirm reliable information through direct interview and discussion using questionnaires to provide guidance in order to minimize misrepresentation.

\subsection{Spatial Analysis using Heatmap}

The purpose of applying heatmap is to ascertain the range of fishing locations, especially for artisan fisheries activities. The results showed the location data with more or less fishing activities, while analyzing the various factors influencing the water selection. Heatmap is described as a graph data type comprising cells with specially assigned colors indicating the level of attribute base on use. In addition, the map highlights the phenomenon object distribution (Eck, 2005), while in contrast, is demonstrated as geographic clusters (Dempsey, 2014). Also, the graph is suggested as a geospatial data involving the use of certain colours to indicate concentration points (Yeap \& Uy, 2014). However, this study processed heatmap using ArcGIS 10.5 with kernel density estimation (KDE).

\subsection{Fuzzy Number}

Fuzzy numbers are a set of unclear parts that are real numbers representing confidence intervals. A Triangular fuzzy number (TFN) contains these basic feature, where a fuzzy number $\tilde{A}$ on $\mathbb{R}$ is TFN when its membership function $\chi \in \tilde{A}, \mu_{\tilde{A}}(x): \mathbb{R} \rightarrow$ $[0,1]$ is equal to (van Laarhoven and Pedrycz, 1983):

$$
\mu_{\tilde{A}}(x)= \begin{cases}(x-k) /(m-k), & k \leq x \leq m \\ (w-x) /(w-m), & m \leq x \leq w \\ 0, & \text { otherwise }\end{cases}
$$

The operational of two TFN appears as follows:

$$
\begin{array}{cc}
\tilde{A}_{1}(+) \tilde{A}_{2}=k_{1}+k_{2}, m_{1}+m_{2}, w_{1}+w_{2} & \tilde{A}_{1}(\times) \tilde{A}_{2}=k_{1} k_{2}, m_{1} m_{2}, w_{1}, w_{2} \\
\tilde{A}_{1}(-) \tilde{A}_{2}=k_{1}-w_{2}, m_{1}+m_{2}, w_{1}+k_{2} & \tilde{A}_{1}(\div) \tilde{A}_{2}=\frac{k_{1}}{w_{2}}, \frac{m_{1}}{m_{2}}, \frac{w_{1}}{k_{2}}
\end{array}
$$

The study also involves the use of expression to measure the individual criteria with five basic linguistic terms, known as"absolutely important," "very strongly important,"essentially important,"“weakly important", and "equally important" with respect to a fuzzy five level scale (Chiou, 2001).

\subsection{Fuzzy DEMATEL}

DEMATEL is one of the known MCDM tools used in building and analysing structural models involving causal relationships between complex factors. More specifically, the method is based on a graph describing the condition of groups of factors acting as causes and those as affected known as 'diagraphs'. The DEMATEL fuzzy steps are as follows:

\section{Step 1. Set goal and defining the evaluation criteria}

The determination of goals and criteria used in this study. This stage indicates the pair-wise comparison scale was evaluated, and comprised of four levels representing "No influence", "Low influence", "High influence", and "Strongly high influence",

\section{Step 2. Directed-relation matrix}

The initial direct-relation matrix $Z$. Experts were asked to generate pairwise comparison, and then measured by criteria $C=$ $\left\{C_{i} \mid i=1,2, \ldots, n\right\}$.

\section{Step 3. Normalized direct-relation fuzzy matrix}

The normalized direct-relation matrix $X$, is obtained by the formula (Wu \& Lee, 2007):

$$
\begin{aligned}
& X=s \cdot Z \\
& s=\frac{1}{\max _{1 \leq i \leq n} \sum_{j=1}^{n} z_{i j}}, \quad i, j=1,2, \ldots, n .
\end{aligned}
$$

\section{Step 4. The total-relation matrix}

The total-relation matrix $T$ is calculated by the equation:

$T=X\left(1-X^{-1}\right.$ 


\section{Step 5. The sum of rows and columns}

The sum of rows and columns are separately denoted as $D$ and $R$ within the total-relation matrix $T$ by the formula:

$$
T=T_{i j} \quad i, j=1,2, \ldots, n, \quad D=\sum_{j=1}^{n} t_{i j}, \quad R=\sum_{j=1}^{n} t_{i j},
$$

\section{Step 6. Analyse the result}

Analyse the criteria into causal and effect diagram by mapping the dataset. Where, the horizontal axis $(D+R)$, and the vertical axis $(D-R)$.

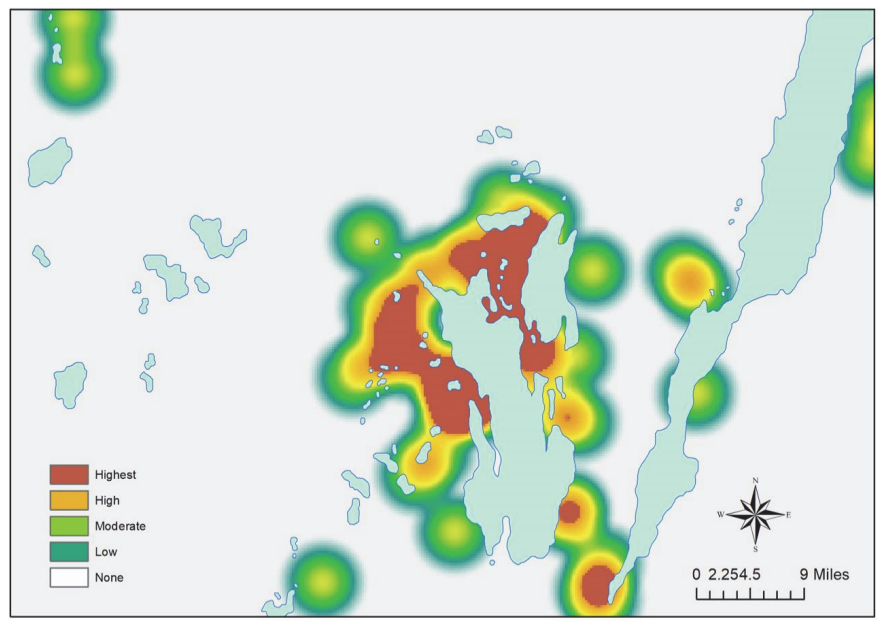

Fig. 2. Heatmap fishing ground in Kei islands for Artisanal Fisheries

\section{Results}

\subsection{Heatmap Analysis}

The field survey results were processed using the Kernel Density Estimation (KDE) approach. Figure 2 shows the heatmap fishing ground has been acquired in Kei Island. In addition, Pulau Kei Kecil, Kei Kecil Water Districts, Manyeuw and Hoat Sorbay in Southeast Maluku Regency, are locations with the highest fishing intensity by local fishermen for a one year period. As for Tual City, the areas around Dullah Island which is close to the Dullah Laut, were observed as the most visited spot. Also, Kei Besar Island, the waters around Feer Village in Kei Besar Selatan Subdistrict, Southeast Maluku Regency were the most preferred choice of fishing ground.

\begin{tabular}{|c|c|c|c|c|c|c|c|c|c|c|c|c|c|}
\hline & $\mathrm{C} 1$ & $\mathrm{C} 2$ & C3 & $\mathrm{C} 4$ & $\mathrm{C} 5$ & C6 & $\mathrm{C} 7$ & $\mathrm{C} 8$ & C9 & $\mathrm{C} 10$ & $\mathrm{C} 11$ & $\mathrm{C} 12$ & $\mathrm{C} 13$ \\
\hline $\mathrm{C} 1$ & 0 & 3 & 3 & 2 & 3 & 4 & 2 & 4 & 3 & 3 & 3 & 4 & 4 \\
\hline $\mathrm{C} 2$ & 3 & 0 & 2 & 2 & 3 & 2 & 1 & 3 & 3 & 3 & 3 & 4 & 4 \\
\hline C3 & 4 & 2 & 0 & 2 & 3 & 2 & 1 & 3 & 1 & 3 & 3 & 4 & 4 \\
\hline $\mathrm{C} 4$ & 3 & 1 & 1 & 0 & 2 & 3 & 1 & 2 & 1 & 1 & 1 & 1 & 1 \\
\hline C5 & 3 & 2 & 3 & 3 & 0 & 3 & 1 & 3 & 3 & 2 & 2 & 2 & 3 \\
\hline C6 & 4 & 2 & 3 & 3 & 3 & 0 & 2 & 3 & 3 & 3 & 4 & 2 & 4 \\
\hline C7 & 2 & 1 & 2 & 1 & 2 & 2 & 0 & 2 & 2 & 2 & 2 & 2 & 3 \\
\hline C8 & 3 & 2 & 3 & 3 & 2 & 3 & 1 & 0 & 2 & 2 & 2 & 4 & 3 \\
\hline C9 & 3 & 1 & 1 & 1 & 2 & 3 & 1 & 2 & 0 & 4 & 4 & 2 & 3 \\
\hline C10 & 3 & 1 & 1 & 1 & 2 & 3 & 1 & 2 & 4 & 0 & 4 & 4 & 4 \\
\hline C11 & 3 & 4 & 3 & 1 & 3 & 3 & 3 & 2 & 4 & 4 & 0 & 2 & 3 \\
\hline $\mathrm{C} 12$ & 3 & 3 & 3 & 1 & 3 & 3 & 2 & 4 & 2 & 4 & 2 & 0 & 3 \\
\hline C13 & 4 & 4 & 4 & 1 & 3 & 4 & 3 & 3 & 4 & 4 & 4 & 2 & 0 \\
\hline
\end{tabular}

Table 1

Assessment on direct relation matrix $\mathrm{T}$

\subsection{Fuzzy DEMATEL}

The criteria for choosing fishing ground spot on artisan fisheries include distance from the village (C1), information by other local fisherman (C2), information passed on by parents (C3), random trip (C4), seasons (C5), capacity of the fishing gears (C6), distance to local market (C7), village customary rights (C8), technology-based information (GPS and fish finder) 
(C9), preliminary survey-based information (C10), targeting specific fish species (C11), avoiding conflict (C12), and areas widely known to have abundant of fishes (C13). These criteria emerged from the results of interviews with local fishermen and verification with researchers related to the field of capture fisheries.

Table 2

Normalized initial direct-relation fuzzy matrix (j)

\begin{tabular}{ccccccccccccccc}
\hline & C1 & C2 & C3 & C4 & C5 & C6 & C7 & C8 & C9 & C10 & C11 & C12 & C13 \\
\hline C1 & 0 & 0.5 & 0.5 & 0.25 & 0.5 & 0.75 & 0.25 & 0.75 & 0.5 & 0.5 & 0.5 & 0.75 & 0.75 \\
C2 & 0.5 & 0 & 0.25 & 0.25 & 0.5 & 0.25 & 0 & 0.5 & 0.5 & 0.5 & 0.5 & 0.75 & 0.75 \\
C3 & 0.75 & 0.25 & 0 & 0.25 & 0.5 & 0.25 & 0 & 0.5 & 0 & 0.5 & 0.5 & 0.75 & 0.75 \\
C4 & 0.5 & 0 & 0 & 0 & 0.25 & 0.5 & 0 & 0.25 & 0 & 0 & 0 & 0 & 0 \\
C5 & 0.5 & 0.25 & 0.5 & 0.5 & 0 & 0.5 & 0 & 0.5 & 0.5 & 0.25 & 0.25 & 0.25 & 0.5 \\
C6 & 0.75 & 0.25 & 0.5 & 0.5 & 0.5 & 0 & 0.25 & 0.5 & 0.5 & 0.5 & 0.75 & 0.25 & 0.75 \\
C7 & 0.25 & 0 & 0.25 & 0 & 0.25 & 0.25 & 0 & 0.25 & 0.25 & 0.25 & 0.25 & 0.25 & 0.5 \\
C8 & 0.5 & 0.25 & 0.5 & 0.5 & 0.25 & 0.5 & 0 & 0 & 0.25 & 0.25 & 0.25 & 0.75 & 0.5 \\
C9 & 0.5 & 0 & 0 & 0 & 0.25 & 0.5 & 0 & 0.25 & 0 & 0.75 & 0.75 & 0.25 & 0.5 \\
C10 & 0.5 & 0 & 0 & 0 & 0.25 & 0.5 & 0 & 0.25 & 0.75 & 0 & 0.75 & 0.75 & 0.75 \\
C11 & 0.5 & 0.75 & 0.5 & 0 & 0.5 & 0.5 & 0.5 & 0.25 & 0.75 & 0.75 & 0 & 0.25 & 0.5 \\
C12 & 0.5 & 0.5 & 0.5 & 0 & 0.5 & 0.5 & 0.25 & 0.75 & 0.25 & 0.75 & 0.25 & 0 & 0.5 \\
C13 & 0.75 & 0.75 & 0.75 & 0 & 0.5 & 0.75 & 0.5 & 0.5 & 0.75 & 0.75 & 0.75 & 0.25 & 0 \\
\hline
\end{tabular}

Table 3

Normalized initial direct-relation fuzzy matrix (y)

\begin{tabular}{cccccccccccccccccccc}
\hline & C1 & C2 & C3 & C4 & C5 & C6 & C7 & C8 & C9 & C10 & C11 & C12 & C13 \\
\hline C1 & 0 & 0.75 & 0.75 & 0.5 & 0.75 & 1 & 0.5 & 1 & 0.75 & 0.75 & 0.75 & 1 & 1 \\
C2 & 0.75 & 0 & 0.5 & 0.5 & 0.75 & 0.5 & 0.25 & 0.75 & 0.75 & 0.75 & 0.75 & 1 & 1 \\
C3 & 1 & 0.5 & 0 & 0.5 & 0.75 & 0.5 & 0.25 & 0.75 & 0.25 & 0.75 & 0.75 & 1 & 1 \\
C4 & 0.75 & 0.25 & 0.25 & 0 & 0.5 & 0.75 & 0.25 & 0.5 & 0.25 & 0.25 & 0.25 & 0.25 & 0.25 \\
C5 & 0.75 & 0.5 & 0.75 & 0.75 & 0 & 0.75 & 0.25 & 0.75 & 0.75 & 0.5 & 0.5 & 0.5 & 0.75 \\
C6 & 1 & 0.5 & 0.75 & 0.75 & 0.75 & 0 & 0.5 & 0.75 & 0.75 & 0.75 & 1 & 0.5 & 1 \\
C7 & 0.5 & 0.25 & 0.5 & 0.25 & 0.5 & 0.5 & 0 & 0.5 & 0.5 & 0.5 & 0.5 & 0.5 & 0.75 \\
C8 & 0.75 & 0.5 & 0.75 & 0.75 & 0.5 & 0.75 & 0.25 & 0 & 0.5 & 0.5 & 0.5 & 1 & 0.75 \\
C9 & 0.75 & 0.25 & 0.25 & 0.25 & 0.5 & 0.75 & 0.25 & 0.5 & 0 & 1 & 1 \\
C10 & 0.75 & 0.25 & 0.25 & 0.25 & 0.5 & 0.75 & 0.25 & 0.5 & 1 & 0 & 1 & 0.5 & 0.75 \\
C11 & 0.75 & 1 & 0.75 & 0.25 & 0.75 & 0.75 & 0.75 & 0.5 & 1 & 1 & 0 \\
C12 & 0.75 & 0.75 & 0.75 & 0.25 & 0.75 & 0.75 & 0.5 & 1 & 0.5 & 1 & 0.5 & 0 & 1 & 0.5 & 0.75 \\
C13 & 1 & 1 & 1 & 0.25 & 0.75 & 1 & 0.75 & 0.75 & 1 & 1 & 1 \\
\hline
\end{tabular}

Table 4

Normalized initial direct-relation fuzzy matrix (m)

\begin{tabular}{|c|c|c|c|c|c|c|c|c|c|c|c|c|c|}
\hline & $\mathrm{C} 1$ & $\mathrm{C} 2$ & C3 & $\mathrm{C} 4$ & $\mathrm{C} 5$ & C6 & C7 & C8 & C9 & $\mathrm{C} 10$ & C11 & C12 & $\mathrm{C} 13$ \\
\hline $\mathrm{C} 1$ & 0 & 1 & 1 & 0.75 & 1 & 1 & 0.75 & 1 & 1 & 1 & 1 & 1 & 1 \\
\hline $\mathrm{C} 2$ & 1 & 0 & 0.75 & 0.75 & 1 & 0.75 & 0.5 & 1 & 1 & 1 & 1 & 1 & 1 \\
\hline $\mathrm{C} 3$ & 1 & 0.75 & 0 & 0.75 & 1 & 0.75 & 0.5 & 1 & 0.5 & 1 & 1 & 1 & 1 \\
\hline $\mathrm{C} 4$ & 1 & 0.5 & 0.5 & 0 & 0.75 & 1 & 0.5 & 0.75 & 0.5 & 0.5 & 0.5 & 0.5 & 0.5 \\
\hline $\mathrm{C} 5$ & 1 & 0.75 & 1 & 1 & 0 & 1 & 0.5 & 1 & 1 & 0.75 & 0.75 & 0.75 & 1 \\
\hline C6 & 1 & 0.75 & 1 & 1 & 1 & 0 & 0.75 & 1 & 1 & 1 & 1 & 0.75 & 1 \\
\hline $\mathrm{C} 7$ & 0.75 & 0.5 & 0.75 & 0.5 & 0.75 & 0.75 & 0 & 0.75 & 0.75 & 0.75 & 0.75 & 0.75 & 1 \\
\hline C8 & 1 & 0.75 & 1 & 1 & 0.75 & 1 & 0.5 & 0 & 0.75 & 0.75 & 0.75 & 1 & 1 \\
\hline C9 & 1 & 0.5 & 0.5 & 0.5 & 0.75 & 1 & 0.5 & 0.75 & 0 & 1 & 1 & 0.75 & 1 \\
\hline $\mathrm{C} 10$ & 1 & 0.5 & 0.5 & 0.5 & 0.75 & 1 & 0.5 & 0.75 & 1 & 0 & 1 & 1 & 1 \\
\hline C11 & 1 & 1 & 1 & 0.5 & 1 & 1 & 1 & 0.75 & 1 & 1 & 0 & 0.75 & 1 \\
\hline $\mathrm{C} 12$ & 1 & 1 & 1 & 0.5 & 1 & 1 & 0.75 & 1 & 0.75 & 1 & 0.75 & 0 & 1 \\
\hline C13 & 1 & 1 & 1 & 0.5 & 1 & 1 & 1 & 1 & 1 & 1 & 1 & 0.75 & 0 \\
\hline
\end{tabular}

Table 5

Total-relation fuzzy matrix (j)

\begin{tabular}{ccccccccccccccc}
\hline & C1 & C2 & C3 & C4 & C5 & C6 & C7 & C8 & C9 & C10 & C11 & C12 & C13 \\
\hline C1 & 0 & 0,0435 & 0,0435 & 0,0217 & 0,0435 & 0,0652 & 0,0217 & 0,0652 & 0,0435 & 0,0435 & 0,0435 & 0,0652 & 0,0652 \\
C2 & 0,0435 & 0 & 0,0217 & 0,0217 & 0,0435 & 0,0217 & 0,0000 & 0,0435 & 0,0435 & 0,0435 & 0,0435 & 0,0652 & 0,0652 \\
C3 & 0,0652 & 0,0217 & 0 & 0,0217 & 0,0435 & 0,0217 & 0,0000 & 0,0435 & 0,0000 & 0,0435 & 0,0435 & 0,0652 & 0,0652 \\
C4 & 0,0435 & 0,0000 & 0,0000 & 0 & 0,0217 & 0,0435 & 0,0000 & 0,0217 & 0,0000 & 0,0000 & 0,0000 & 0,0000 & 0,0000 \\
C5 & 0,0435 & 0,0217 & 0,0435 & 0,0435 & 0 & 0,0435 & 0,0000 & 0,0435 & 0,0435 & 0,0217 & 0,0217 & 0,0217 & 0,0435 \\
C6 & 0,0652 & 0,0217 & 0,0435 & 0,0435 & 0,0435 & 0 & 0,0217 & 0,0435 & 0,0435 & 0,0435 & 0,0652 & 0,0217 & 0,0652 \\
C7 & 0,0217 & 0,0000 & 0,0217 & 0,0000 & 0,0217 & 0,0217 & 0 & 0,0217 & 0,0217 & 0,0217 & 0,0217 & 0,0217 & 0,0435 \\
C8 & 0,0435 & 0,0217 & 0,0435 & 0,0435 & 0,0217 & 0,0435 & 0,0000 & 0 & 0,0217 & 0,0217 & 0,0217 & 0,0652 & 0,0435 \\
C9 & 0,0435 & 0,0000 & 0,0000 & 0,0000 & 0,0217 & 0,0435 & 0,0000 & 0,0217 & 0 & 0,0652 & 0,0652 & 0,0217 & 0,0435 \\
C10 & 0,0435 & 0,0000 & 0,0000 & 0,0000 & 0,0217 & 0,0435 & 0,0000 & 0,0217 & 0,0652 & 0 & 0,0652 & 0,0652 & 0,0652 \\
C11 & 0,0435 & 0,0652 & 0,0435 & 0,0000 & 0,0435 & 0,0435 & 0,0435 & 0,0217 & 0,0652 & 0,0652 & 0 & 0,0217 & 0,0435 \\
C12 & 0,0435 & 0,0435 & 0,0435 & 0,0000 & 0,0435 & 0,0435 & 0,0217 & 0,0652 & 0,0217 & 0,0652 & 0,0217 & 0 & 0,0435 \\
C13 & 0,0652 & 0,0652 & 0,0652 & 0,0000 & 0,0435 & 0,0652 & 0,0435 & 0,0435 & 0,0652 & 0,0652 & 0,0652 & 0,0217 & 0
\end{tabular}


Table 6

Total-relation fuzzy matrix (y).

\begin{tabular}{|c|c|c|c|c|c|c|c|c|c|c|c|c|c|}
\hline & $\mathrm{C} 1$ & $\mathrm{C} 2$ & $\mathrm{C} 3$ & $\mathrm{C} 4$ & C5 & C6 & C7 & C8 & C9 & C10 & C11 & C12 & C13 \\
\hline $\mathrm{C} 1$ & 0 & 0.0652 & 0.0652 & 0.0435 & 0.0652 & 0.0870 & 0.0435 & 0.0870 & 0.0652 & 0.0652 & 0.0652 & 0.0870 & 0.0870 \\
\hline $\mathrm{C} 2$ & 0.0652 & 0 & 0.0435 & 0.0435 & 0.0652 & 0.0435 & 0.0217 & 0.0652 & 0.0652 & 0.0652 & 0.0652 & 0.0870 & 0.0870 \\
\hline $\mathrm{C} 3$ & 0.0870 & 0.0435 & 0 & 0.0435 & 0.0652 & 0.0435 & 0.0217 & 0.0652 & 0.0217 & 0.0652 & 0.0652 & 0.0870 & 0.0870 \\
\hline $\mathrm{C} 4$ & 0.0652 & 0.0217 & 0.0217 & 0 & 0.0435 & 0.0652 & 0.0217 & 0.0435 & 0.0217 & 0.0217 & 0.0217 & 0.0217 & 0.0217 \\
\hline C5 & 0.0652 & 0.0435 & 0.0652 & 0.0652 & 0 & 0.0652 & 0.0217 & 0.0652 & 0.0652 & 0.0435 & 0.0435 & 0.0435 & 0.0652 \\
\hline C6 & 0.0870 & 0.0435 & 0.0652 & 0.0652 & 0.0652 & 0 & 0.0435 & 0.0652 & 0.0652 & 0.0652 & 0.0870 & 0.0435 & 0.0870 \\
\hline C7 & 0.0435 & 0.0217 & 0.0435 & 0.0217 & 0.0435 & 0.0435 & 0 & 0.0435 & 0.0435 & 0.0435 & 0.0435 & 0.0435 & 0.0652 \\
\hline $\mathrm{C} 8$ & 0.0652 & 0.0435 & 0.0652 & 0.0652 & 0.0435 & 0.0652 & 0.0217 & 0 & 0.0435 & 0.0435 & 0.0435 & 0.0870 & 0.0652 \\
\hline C9 & 0.0652 & 0.0217 & 0.0217 & 0.0217 & 0.0435 & 0.0652 & 0.0217 & 0.0435 & 0 & 0.0870 & 0.0870 & 0.0435 & 0.0652 \\
\hline $\mathrm{C} 10$ & 0.0652 & 0.0217 & 0.0217 & 0.0217 & 0.0435 & 0.0652 & 0.0217 & 0.0435 & 0.0870 & 0 & 0.0870 & 0.0870 & 0.0870 \\
\hline $\mathrm{C} 11$ & 0.0652 & 0.0870 & 0.0652 & 0.0217 & 0.0652 & 0.0652 & 0.0652 & 0.0435 & 0.0870 & 0.0870 & 0 & 0.0435 & 0.0652 \\
\hline $\mathrm{C} 12$ & 0.0652 & 0.0652 & 0.0652 & 0.0217 & 0.0652 & 0.0652 & 0.0435 & 0.0870 & 0.0435 & 0.0870 & 0.0435 & 0 & 0.0652 \\
\hline $\mathrm{C} 13$ & 0.0870 & 0.0870 & 0.0870 & 0.0217 & 0.0652 & 0.0870 & 0.0652 & 0.0652 & 0.0870 & 0.0870 & 0.0870 & 0.0435 & 0 \\
\hline
\end{tabular}

Table 7

Total-relation fuzzy matrix $(\mathrm{y})$

\begin{tabular}{cccccccccccccccc}
\hline & C1 & C2 & C3 & C4 & C5 & C6 & C7 & C8 & C9 & C10 & C11 & C12 & C13 \\
\hline C1 & 0 & 0.0870 & 0.0870 & 0.0652 & 0.0870 & 0.0870 & 0.0652 & 0.0870 & 0.0870 & 0.0870 & 0.0870 & 0.0870 & 0.0870 \\
C2 & 0.0870 & 0 & 0.0652 & 0.0652 & 0.0870 & 0.0652 & 0.0435 & 0.0870 & 0.0870 & 0.0870 & 0.0870 & 0.0870 & 0.0870 \\
C3 & 0.0870 & 0.0652 & 0 & 0.0652 & 0.0870 & 0.0652 & 0.0435 & 0.0870 & 0.0435 & 0.0870 & 0.0870 & 0.0870 & 0.0870 \\
C4 & 0.0870 & 0.0435 & 0.0435 & 0 & 0.0652 & 0.0870 & 0.0435 & 0.0652 & 0.0435 & 0.0435 & 0.0435 & 0.0435 & 0.0435 \\
C5 & 0.0870 & 0.0652 & 0.0870 & 0.0870 & 0 & 0.0870 & 0.0435 & 0.0870 & 0.0870 & 0.0652 & 0.0652 & 0.0652 & 0.0870 \\
C6 & 0.0870 & 0.0652 & 0.0870 & 0.0870 & 0.0870 & 0 & 0.0652 & 0.0870 & 0.0870 & 0.0870 & 0.0870 & 0.0652 & 0.0870 \\
C7 & 0.0652 & 0.0435 & 0.0652 & 0.0435 & 0.0652 & 0.0652 & 0 & 0.0652 & 0.0652 & 0.0652 & 0.0652 & 0.0652 & 0.0870 \\
C8 & 0.0870 & 0.0652 & 0.0870 & 0.0870 & 0.0652 & 0.0870 & 0.0435 & 0 & 0.0652 & 0.0652 & 0.0652 & 0.0870 & 0.0870 \\
C9 & 0.0870 & 0.0435 & 0.0435 & 0.0435 & 0.0652 & 0.0870 & 0.0435 & 0.0652 & 0 & 0.0870 & 0.0870 & 0.0652 & 0.0870 \\
C10 & 0.0870 & 0.0435 & 0.0435 & 0.0435 & 0.0652 & 0.0870 & 0.0435 & 0.0652 & 0.0870 & 0 & 0.0870 & 0.0870 & 0.0870 \\
C11 & 0.0870 & 0.0870 & 0.0870 & 0.0435 & 0.0870 & 0.0870 & 0.0870 & 0.0652 & 0.0870 & 0.0870 & 0 & 0.0652 & 0.0870 \\
C12 & 0.0870 & 0.0870 & 0.0870 & 0.0435 & 0.0870 & 0.0870 & 0.0652 & 0.0870 & 0.0652 & 0.0870 & 0.0652 & 0 & 0.0870 \\
C13 & 0.0870 & 0.0870 & 0.0870 & 0.0435 & 0.0870 & 0.0870 & 0.0870 & 0.0870 & 0.0870 & 0.0870 & 0.0870 & 0.0652 & 0 \\
\hline
\end{tabular}

Table 8

Crisp values Di+Ri and Di-Ri

\begin{tabular}{ccccc}
\hline Criteria & Di+Ri & Di-Ri & Criteria & Di+Ri \\
\hline C1 & 7.4104 & -0.0067 & C 8 & 6.5412 \\
C2 & 6.2236 & 0.4794 & C9 & 6.2636 \\
C3 & 6.3961 & 0.1443 & C10 & -0.1934 \\
C4 & 4.6939 & -0.2476 & C11 & 6.6402 \\
C5 & 6.4781 & -0.0853 & C12 & 6.9392 \\
C6 & 7.0946 & 0.0075 & C13 & 6.6653 \\
C7 & 4.9566 & 0.2486 & & 7.4956 \\
\hline
\end{tabular}

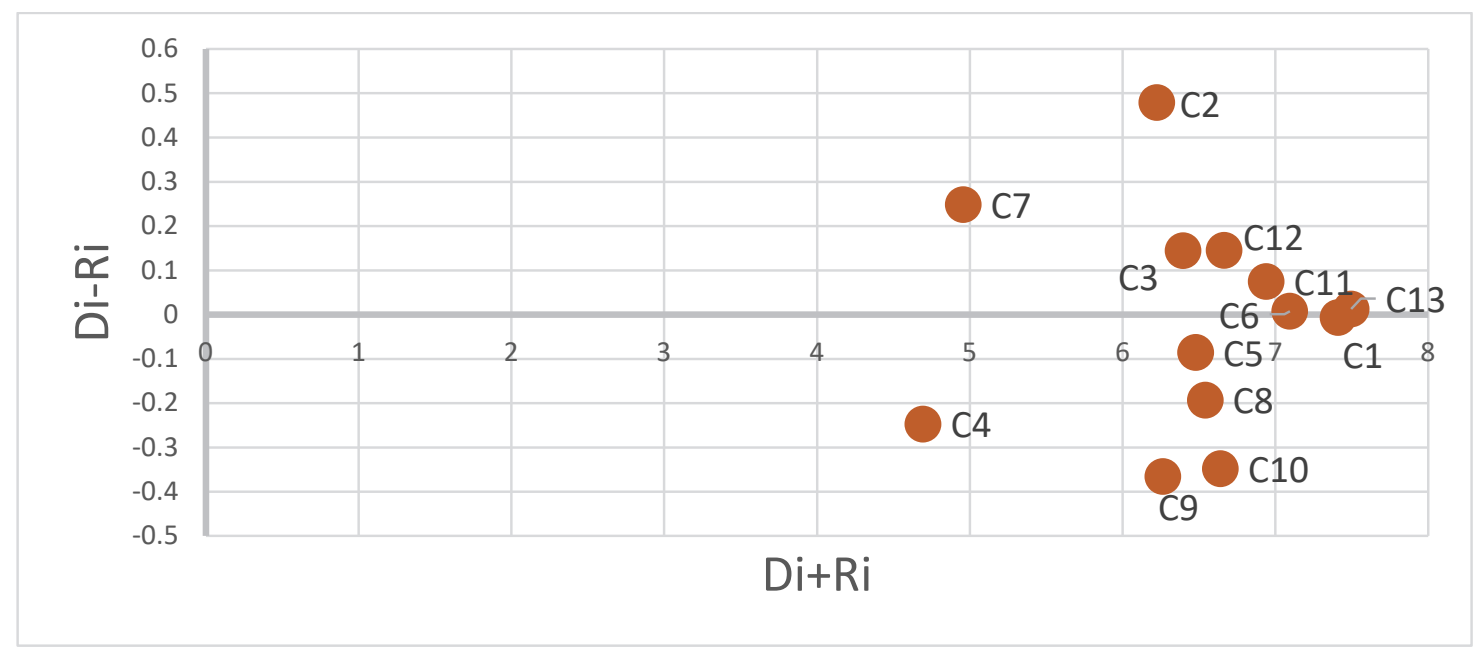

Fig. 3. Cause and effect diagram

Table 8 represents the results of local fishermen assessment on existing criteria. Furthermore, the three fuzzy values were divided into three parts $(\mathrm{j}, \mathrm{y}$ and $\mathrm{m}$ ) for the normalized core table of direct-relation fuzzy matrix (Table 2-4) and totalrelation fuzzy matrix (Tables 5-7). Causal-effect calculation results show (Table 8 and Fig. 3) criteria acting as causal, were 
information obtained from other local fishermen (C2), information passed on by parents (C3), capacity of fishing gears (C6) , distance to local market (C7), targeting specific fish species (C11), avoiding conflict (C12), and areas widely known to have abundant of fishes (C13). While the criteria included in the effect category are distance from the village $(\mathrm{C} 1)$, random trip (C4), seasons (C5), village customary rights (C8), technology-based information (GPS and fish finder) (C9), and preliminary survey-based information $(\mathrm{C} 10)$.

\section{Discussion}

The results showed the fishing ground location in Kei Islands provides 3 densest spots to serve as fishing ground throughout the year. However, the condition possesses some consequences for the overall sustainable marine resources as this activity continues. Therefore, it is highly necessary to educate more fishermen in order to reduce the threat to fish supplies in this region. Several factors instigate the behaviour of local fishermen in choosing fishing locations. Habitual, economics and technological capacity are some of the primary drivers. The results of causal-effect diagrams provide comprehensive information recognizing the causal as the main concern due to the criteria in this category are very complex to modify (Hori \& Shimizu, 1999). Therefore, the most influential factor considered is the information from other local fishermen (C2) due to the highest Di-Ri value acquired, followed by distance to local market (C7), and avoiding conflict (C12). Nevertheless, among the three highest causal factors, $\mathrm{C} 12$ has a greater $\mathrm{Di}+\mathrm{Ri}$ value to favor $\mathrm{C} 12$ with a greater influence than the others. However, C13 observes the major $\mathrm{Di}+\mathrm{Ri}$ value, in addition to obtaining the largest causal factor, while C9 is the effect factor due to highest Di-Ri. Therefore, the regional government serves as a policy maker for Southeast Maluku District and Tual City with the responsibility to address the seven existing causal factors. Subsequently, the purpose is to facilitate the education of local fishermen in coastal communities. This is achieved through the provision of extensive fishing spots close to market locations, as small areas potentially tend to result to conflict. The six effect factors can at any time turn into causal. Therefore, technology-based information (GPS and fish finder) (C9), and preliminary survey-based information (C10) are highly considered by their respective local governments more specifically. However, both factors are achieved by involving higher educational institutions to support in mapping the fishing locations and fishing ground density conditions. This is to prevent the problem of overfishing, and further sustain marine resources.

\section{Conclusion}

There are presently only three functional fishing locations, including the central sites on Kei islands. This lingering situation is a threat to sustainable marine resources and the entire water ecosystem. Therefore, the two regional governments in Kei Islands, Southeast Maluku Regency and Tual City, are advised to pay close attention to developing the knowledge of fishermen. One significant applicable recommendation is to establish fish hubs close to fishing villages. This is expected to prevent fishermen from exploring waters close to the local markets. In addition, the two local governments are encouraged to further improve on the application of modern technology, specifically in terms of mapping fishing potentials. This is important in analyzing the density of fishing locations due to lack of knowledge by local fishermen on marine potentials. These efforts are imperative in the context of the sustainable marine resources. Further researches are recommended to explore the results generated from conducting this investigation on the potential of marine resources and surrounding ecosystems in the waters of Kei islands.

\section{Acknowledgements}

The authors are grateful to the Directorate of Research and Community Service, Ministry of Research and Technology, the Higher Education Republic of Indonesia, for funding this research under PTUPT Scheme 2018-2020.

\section{References}

Adamides, E. D., Mitropoulos, P., Giannikos, I., \& Mitropoulos, I. (2009). A multi-methodological approach to the development of a regional solid waste management system. Journal of the Operational Research Society, 60(6), 758770.

Barkin, J. S., \& DeSombre, E. R. (2013). Saving global fisheries: reducing fishing capacity to promote sustainability. Mit Press.

Castilla, J. C., \& Defeo, O. (2001). Latin American benthic shellfisheries: emphasis on co-management and experimental practices. Reviews in Fish Biology and Fisheries, 11(1), 1-30.

Chang, B., Chang, C. W., \& Wu, C. H. (2011). Fuzzy DEMATEL method for developing supplier selection criteria. Expert systems with Applications, 38(3), 1850-1858.

Chen, I. S. (2016). A combined MCDM model based on DEMATEL and ANP for the selection of airline service quality improvement criteria: A study based on the Taiwanese airline industry. Journal of Air Transport Management, 57, 718.

Chiou, H. K. (2001). Fuzzy hierarchical evaluation with grey relation model of green engineering for industry. International Journal of Fuzzy Systems, 3(3), 466-475.

Chiu, W. Y., Tzeng, G. H., \& Li, H. L. (2013). A new hybrid MCDM model combining DANP with VIKOR to improve estore business. Knowledge-Based Systems, 37, 48-61.

Defeo, O., \& Castilla, J. C. (2005). More than one bag for the world fishery crisis and keys for co-management successes in selected artisanal Latin American shellfisheries. Reviews in Fish Biology and Fisheries, 15(3), 265-283. 
Eck, J., Chainey, S., Cameron, J., \& Wilson, R. (2005). Mapping crime: Understanding hotspots. Retrieved from https://www.ncjrs.gov/pdffiles1/nij/209393.pdf.

Gabus, A., \& Fontela, E. (1972). World problems, an invitation to further thought within the framework of DEMATEL battelle institute. Geneva research centre.

Govindan, K., Rajendran, S., Sarkis, J., \& Murugesan, P. (2015). Multi criteria decision making approaches for green supplier evaluation and selection: a literature review. Journal of Cleaner Production, 98, 66-83.

Hall, S. J., \& Mainprize, B. M. (2005). Managing by-catch and discards: how much progress are we making and how can we do better?. Fish and Fisheries, 6(2), 134-155.

Hamid, S. K., Teniwut, W. A., Teniwut, R. M., Rahantoknam, M. A., Hasyim, C. L., \& Hungan, M. (2017, October). The Support of MPA (Marine Protected Area) in Coral Triangle Area: Evidence from Kei Islands, Indonesia. In IOP Conference Series: Earth and Environmental Science (Vol. 89, No. 1, p. 012025).

Hori, S., \& Shimizu, Y. (1999). Designing methods of human interface for supervisory control systems. Control Engineering Practice, 7(11), 1413-1419.

Kandakoglu, A., Celik, M., \& Akgun, I. (2009). A multi-methodological approach for shipping registry selection in maritime transportation industry. Mathematical and Computer Modelling, 49(3-4), 586-597.

Kiker, G. A., Bridges, T. S., Varghese, A., Seager, T. P., \& Linkov, I. (2005). Application of multicriteria decision analysis in environmental decision making. Integrated Environmental Assessment and Management: An International Journal, 1(2), 95-108.

Klein, C. J., Steinback, C., Watts, M., Scholz, A. J., \& Possingham, H. P. (2010). Spatial marine zoning for fisheries and conservation. Frontiers in Ecology and the Environment, 8(7), 349-353.

Lee, K. H., \& Wu, Y. (2014). Integrating sustainability performance measurement into logistics and supply networks: A multi-methodological approach. The British Accounting Review, 46(4), 361-378.

Lin, R. J. (2013). Using fuzzy DEMATEL to evaluate the green supply chain management practices. Journal of Cleaner Production, 40, 32-39.

Liu, C. H., Tzeng, G. H., \& Lee, M. H. (2012). Improving tourism policy implementation-The use of hybrid MCDM models. Tourism Management, 33(2), 413-426.

Myers, R. A., \& Worm, B. (2003). Rapid worldwide depletion of predatory fish communities. Nature, 423(6937), $280-283$.

Netek, R., Pour, T., \& Slezakova, R. (2018). Implementation of heat maps in geographical information system-exploratory study on traffic accident data. Open Geosciences, 10(1), 367-384.

Pauly, D., Alder, J., Bennett, E., Christensen, V., Tyedmers, P., \& Watson, R. (2003). The future for fisheries. Science, 302(5649), 1359-1361.

Ren, L., Zhang, L., Tao, F., Zhang, X., Luo, Y., \& Zhang, Y. (2012). A methodology towards virtualisation-based high performance simulation platform supporting multidisciplinary design of complex products. Enterprise Information Systems, 6(3), 267-290.

Rezaei, J. (2015). Best-worst multi-criteria decision-making method. Omega, 53, 49-57.

Teniwut, W. A. (2016). For sustainable revenue of fisheries sector in small islands: evidence of Maluku, Indonesia. Aquaculture, Aquarium, Conservation \& Legislation, 9(3), 722-732.

Teniwut, W. A., \& Teniwut, R. M. (2018). Minimizing the instability of seaweed cultivation productivity on rural coastal area: a case study from Indonesia. Aquaculture, Aquarium, Conservation \& Legislation, 11(1), 259-271.

Tzeng, G. H., Chiang, C. H., \& Li, C. W. (2007). Evaluating intertwined effects in e-learning programs: A novel hybrid MCDM model based on factor analysis and DEMATEL. Expert systems with Applications, 32(4), 1028-1044.

Van Laarhoven, P. J., \& Pedrycz, W. (1983). A fuzzy extension of Saaty's priority theory. Fuzzy sets and Systems, 11(1-3), 229-241.

Vujanović, D., Momčilović, V., Bojović, N., \& Papić, V. (2012). Evaluation of vehicle fleet maintenance management indicators by application of DEMATEL and ANP. Expert Systems with Applications, 39(12), 10552-10563.

Wang, J. J., Jing, Y. Y., Zhang, C. F., \& Zhao, J. H. (2009). Review on multi-criteria decision analysis aid in sustainable energy decision-making. Renewable and Sustainable Energy Reviews, 13(9), 2263-2278.

Wu, W. W., \& Lee, Y. T. (2007). Developing global managers' competencies using the fuzzy DEMATEL method. Expert Systems with Applications, 32(2), 499-507.

Yeap, E., \& Uy, I. (2020). Marker Clustering and Heatmaps: New Features in the Google Maps Android API Utility Library. 2014. Google Geo Developers. Available online: http:/googlegeodevelopers.blogspot.com/2014/02/marker-clusteringand-heatmaps-new.html. (accessed on 2020-04-12)

Zopounidis, C., \& Doumpos, M. (2002). Multi-criteria decision aid in financial decision making: methodologies and literature review. Journal of Multi-Criteria Decision Analysis, 11(4-5), 167-186.

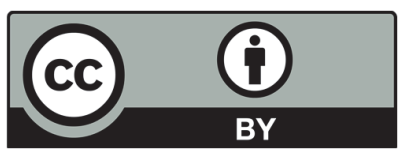

(C) 2020 by the authors; licensee Growing Science, Canada. This is an open access article distributed under the terms and conditions of the Creative Commons Attribution (CC-BY) license (http://creativecommons.org/licenses/by/4.0/). 